\title{
Bloqueo del ganglio esfenopalatino, una opción para el tratamiento de la cefalea postpunción dural
}

\author{
Rosa Sousa S. ${ }^{1,2}$, Opolski I.1,2, Faria P. ${ }^{1,2}$, Grande Carstens M. ${ }^{1,2}$, Voltolini G. ${ }^{1,2}$, Lorena Gomes R. ${ }^{1,2}$, Branco \\ Ferreira S. ${ }^{1,2}$ \\ 1 Hospital e Maternidade São José dos Pinhais, São José dos Pinhais, Brasil. \\ 2 Escola de Saúde Pública de São José dos Pinhais, São José dos Pinhais, Brasil. \\ Introducción: La cefalea postpunción dural (CPPD) es una complicación de la anestesia neuroaxial. Su incidencia \\ varía con el tamaño, formato de la aguja y otros factores. El dolor es descrito como intenso, generalmente, fronto- \\ occipital y con empeoramiento en ortostasis. El abordaje inicial de la CPPD consiste en tratamiento de soporte. En \\ caso de falla terapéutica, el parche sanguíneo epidural (PSE) es el tratamiento de elección, siendo el bloqueo del gan- \\ glio esfenopalatino (BGEP) una alternativa eficaz.
}

Método: Revisión en las bases de datos, comparando con el informe de caso presentado.

Informe: Femenino, 43 años, $63 \mathrm{~kg}$, ASA P1, admitida para colecistectomía abierta. Se optó por el bloqueo epidural del neuroeje, en el cual se produjo una perforación inadvertida de la duramadre, con aguja de Tuohy, calibre 18. La paciente evolucionó, luego de 48 horas, con CPPD, holocraneal, intensidad 10 en la Escala de Clasificación Numérica $0-10$, con empeoramiento al levantarse y alivio en decúbito, sin rigidez cervical o déficit focales. Inicialmente, se optó por un abordaje conservador. Se procedió a hidratación intravenosa $(2,0 \mathrm{~L})$, hidrocortisona $200 \mathrm{mg} /$ día, ketoprofeno $200 \mathrm{mg} /$ día y cafeína $500 \mathrm{mg} /$ día, sin mejora significativa de los síntomas. Se propuso la realización del PSE, al cual la paciente se negó. Frente a la contraindicación absoluta al procedimiento que es la negación, se ofreció la posibilidad del BGEP. Con autorización de la paciente, se realizó el BGEP, en ambiente monitoreado, posición supina, con una ligera extensión cervical. Paralelamente al suelo de la nariz, se introdujeron dos aplicadores con punta de algodón, embebidos en $4 \mathrm{ml}$ de ropivacaína $1 \%$, hasta la pared posterior de ambas fosas nasales, hasta sentir una resistencia. Luego de 5, 10 y 15 minutos, $1 \mathrm{ml}$ del anestésico fue instilado por los cables de los aplicadores, los cuales permanecieron en la cavidad nasal durante 15 minutos. El alivio de los síntomas fue inmediato. La paciente permaneció monitoreada durante una hora y, posteriormente, fue trasladada a sala común. La mañana siguiente, fue dada de alta hospitalaria. Se contactó a la paciente transcurridos cinco días y no relató dolor.

Conclusión: El BGEP por abordaje transnasal es una técnica mínimamente invasiva, eficaz y puede evitar la realización de PSE, atenuando los síntomas de la vasodilatación cerebral inducida, por el estímulo parasimpático, transmitido por medio de las neuronas que tienen sinapsis en el ganglio esfenopalatino. La duración del efecto analgésico continúa indefinida. En el caso relatado, el bloqueo provocó alivio prolongado.

https://doi.org/10.25237/congresoclasa2019.06 